\title{
Diagnosis of susceptibility to malignant hyperthermia with flanking DNA markers
}

\author{
J M Sandra Healy, James JA Heffron, Mary Lehane, Dan G Bradley, Keith Johnson, \\ Tommie V McCarthy
}

\begin{abstract}
Objective-To define the region on human chromosome 19 carrying the gene for malignant hyperthermia susceptibility and to evaluate the use of flanking DNA markers in diagnosing susceptibility.

Design-Prospective molecular genetic linkage studies in a large malignant hyperthermia pedigree.

Setting-Irish malignant hyperthermia testing centre.
\end{abstract}

Subjects-A large Irish malignant hyperthermia pedigree.

Main outcome measures-Routine diagnosis of susceptibility to malignant hyperthermia with in vitro contracture test on muscle biopsy specimens and genetic linkage between susceptibility and polymorphic DNA markers in a malignant hyperthermia family.

Results-Genetic typing of polymorphic DNA markers in a large Irish malignant hyperthermia pedigree generated a lod score of $>\mathbf{3}$ for the marker D19S9 and showed that the gene for susceptibility is flanked by the markers D19S9 and D19S16. These tightly linked flanking markers allowed non-invasive presymptomatic diagnosis of susceptibility in five untested subjects in the large pedigree with an accuracy of $>99.7 \%$.

Conclusions-DNA markers flanking the gene for susceptibility to malignant hyperthermia can be used with high accuracy to diagnose susceptibility in subjects in large known malignant hyperthermia pedigrees and may replace the previous in vitro in large families with malignant hyperthermia.

Republic of Ireland

J M Sandra Healy, BSC,

graduate student, department of biochemistry

James J A Heffron, PHD, associate professor of biochemistry

Mary Lehane, FFARCSI, consultant anaesthetist

Tommie V McCarthy, PHD,

lecturer in biochemistry

Department of Genetics, Trinity College, Dublin 2, Republic of Ireland

Dan G Bradley, PHD,

postdoctoral fellow in genetics

Department of Anatomy, Charing Cross and Westminster Medical

School, London W6 8RF

Keith Johnson, PHD, lecturer

Correspondence and reprint requests to: Dr McCarthy.

BMF 1991;303:1225-8

\section{Introduction}

Malignant hyperthermia is an inherited disorder of human skeletal muscle of unknown aetiology and is one of the major causes of death due to anaesthesia. ${ }^{12}$ It is categorised as a metabolic disorder of skeletal muscle ${ }^{34}$ and it can be triggered in susceptible people by all commonly used inhaled anaesthetics, such as halothane, and by depolarising muscle relaxants, such as succinylcholine. ${ }^{15}$ The classic presentation is a progressive rise in body temperature at a rate of $2^{\circ} \mathrm{C}$ an hour or more, a profoundly accelerated muscle metabolism, contractures, metabolic acidosis, and tachycardia. ${ }^{15}$ Once initiated, a futile metabolic cycle is established and a fulminant syndrome evolves in which Many susceptible patients present with some, but not all, of the classic signs with variable intensity when exposed to agents known to induce the condition. Some known susceptible patients have had previous triggering anaesthetics without any complications. ${ }^{15}$ Thus the early clinical diagnosis of malignant hyperthermia is often difficult. contracture test for diagnosing this inherited disorder

The reported incidence of malignant hyperthermia ranges from about $1 / 10000$ to $1 / 50000$ anaesthetic procedures with an apparently higher incidence in children. ${ }^{67}$ Mortality from malignant hyperthermia is high unless the episode is treated promptly with the muscle relaxant dantrolene ${ }^{125}$; even then, deaths occur in $10-20 \%$ of subjects. ${ }^{12}$

Recently a standardised test was established and validated by the European Malignant Hyperpyrexia Group for investigating susceptibility to malignan hyperthermia in individual subjects. ${ }^{8}$ This test is based on the contractures induced in muscle in vitro by caffeine and halothane and allows the following diagnoses: malignant hyperthermia susceptible (low threshold for contractures induced by caffeine and halothane), malignant hyperthermia normal, and malignant hyperthermia equivocal (low threshold for contractures induced by caffeine or halothane but not both). To date over 40 subjects who survived a clinical episode of malignant hyperthermia have been investigated with the European contracture test: $88 \%$ have been designated susceptible and $12 \%$ equivocal. $^{9}$

Susceptibility to malignant hyperthermia is inherited as an autosomal dominant trait with complete penetrance in most families investigated to date. ${ }^{10-12}$ This inheritance pattern supports the hypothesis that susceptibility is due to a single gene defect. Separate studies reported that about a third of subjects with a diagnosis of susceptibility will actually develop malignant hyperthermia when given a triggering agent - that is, the apparent penetrance of malignant hyperthermia is about $0 \cdot 33 .^{13}$ Therefore, it seems that other genetic or external factors, or both, influence triggering of malignant hyperthermia in susceptible subjects.

Although the biochemical defect responsible for the body temperature may exceed $43^{\circ} \mathrm{C}\left(109 \cdot 4^{\circ} \mathrm{F}\right)$. that malignant hyperthermia is a disorder of regulation of the intracellular free calcium concentration of skeletal muscle. ${ }^{145}$ Biochemical studies of porcine malignant hyperthermia, a disorder clinically and biochemically similar to human malignant hyperthermia, strongly suggest that the primary defect is in the calcium induced calcium release channel of skeletal muscle, which is commonly known as the ryanodine receptor (RYRl). . $^{14-18}$

Recently genetic linkage analysis has been used by us and others to identify the chromosomal location of the gene for susceptibility. ${ }^{112}$ Genetic linkage analysis is a method that allows the localisation of genes for inherited disorders in the absence of any information about the biochemical defects that cause such disorders. ${ }^{1920}$ It relies on the availability of DNA from large families with the disorder and the detection of naturally occurring variations (polymorphisms) in the DNA sequence at the same locations on homologous chromosomes. These variations are detected with DNA probes and with enzymes which cleave DNA at 
specific points, and they are known as restriction fragment length polymorphisms (RFLPs). Restriction fragment length polymorphisms serve as markers for the alleles of a given locus on a pair of homologous chromosomes and allow each allele to be traced in family segregation studies. Linkage analysis is based on the investigation of the segregation patterns of the alleles of a large number of polymorphic DNA markers distributed throughout the entire genome with the disease phenotype in affected families.

If an allele of a DNA marker is linked to a disease gene they will tend to cosegregate during meiosis, owing to the fact that meiotic recombination occurs infrequently between closely linked loci. The closer
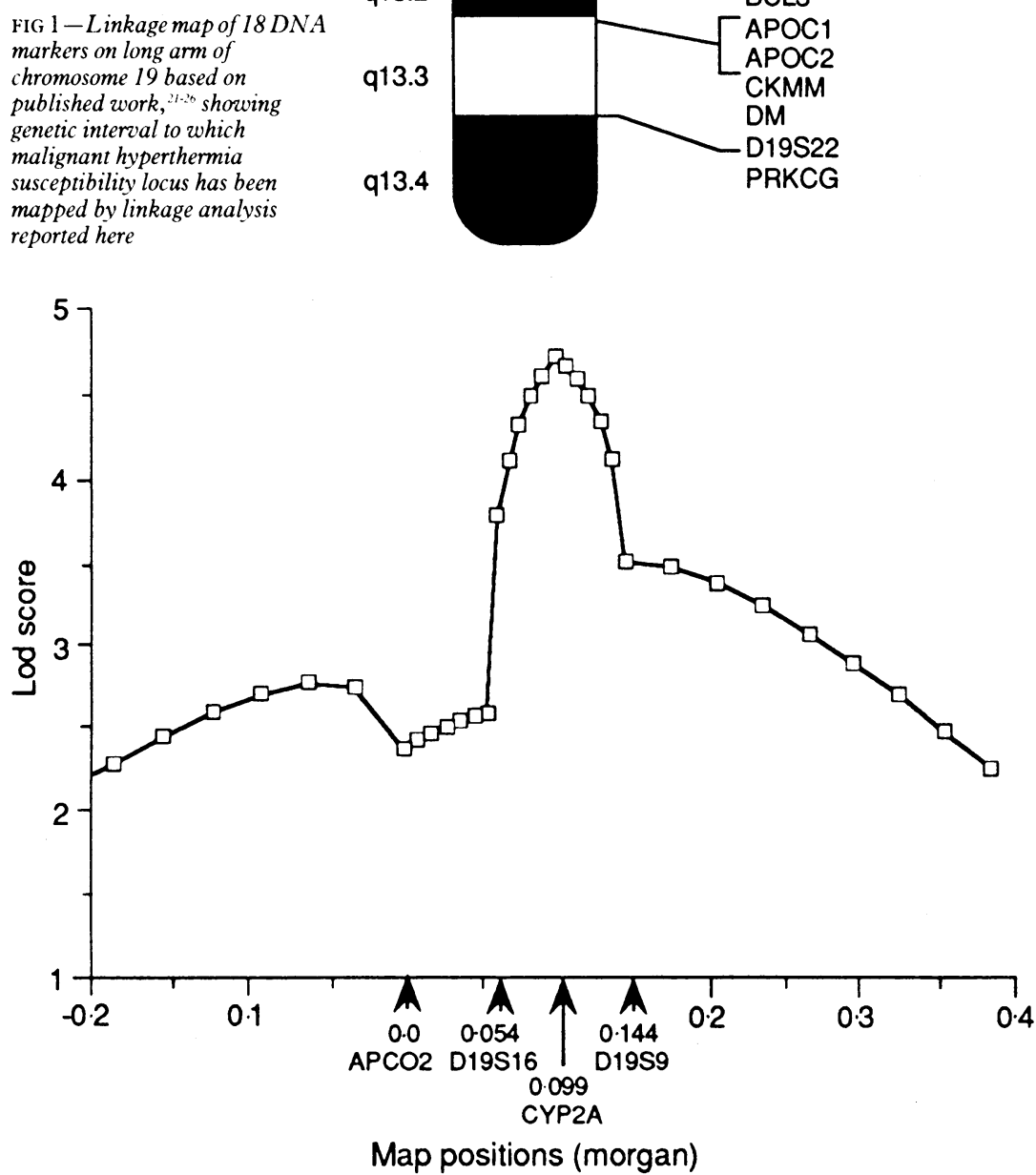

FIG 2-Location map summarising the results of multipoint linkage analysis calculated for malignan hyperthermia susceptibility at various map positions in a fixed marker map. Foint likelihoods were calculated for four loci simultaneously. Support for linkage of susceptibility gene was calculated at various map locations within a fixed map of polymorphic markers; the most likely location is at CYP2A with a lod score of 4·73. Markers were arbitrarily set as shown, according to linkage maps published for this region?." that the allele of the marker is to the disease gene the higher the likelihood that the two will cosegregate in a family because the frequency of recombination between linked loci decreases as the distance between the allele of the marker and the disease gene decreases. ${ }^{13}$ Therefore the frequency of recombination events reflects the genetic distance between two loci, and this distance is expressed by 0 , the frequency of recombination. The strength of the linkage between the two loci is expressed as a probability function, known as the lod score; the lod score itself is a common logarithm (to base 10) - for example, a lod score of 3 indicates a probability of 1000:1 and represents the likelihood of observing the data if the loci are separated by the distance $\theta$ compared with the likelihood of observing the data if the two loci are completely unlinked (defined by $\theta=0 \cdot 5$ ). By convention, a lod score of 3 is considered "proof" of linkage. If the score is highest when the value of $\theta$ is low (approaching zero), the two loci are close together. Once the allele of a marker which is associated with an inherited disorder is identified by linkage analysis, it can be used directly in diagnosing the genetic disorder in individual members of affected families. These markers can also be used as starting points to allow the eventual isolation and identification of the abnormal gene which is responsible for the inherited disorder. ${ }^{19} 20$

As part of a study aimed at identifying the defective gene which causes susceptibility to malignant hyperthermia we recently carried out linkage analysis on susceptible families using polymorphic DNA markers and showed that the causative gene maps to the q12$13 \cdot 2$ region of human chromosome 19 (fig 1) and is flanked by the DNA markers D19S9 and APOC2." Independent studies by MacKenzie et al showed that the human ryanodine receptor gene, like the gene for susceptibility to malignant hyperthermia, also lies between the markers D19S9 and APOC2 on chromosome 19. ${ }^{27}$ Furthermore, polymorphic DNA markers for the ryanodine receptor gene cosegregate with the gene for susceptibility to malignant hyperthermia in several families studied to date. ${ }^{12}$ Taken together with the biochemical evidence above, these results indicate that a defect in the ryanodine receptor gene of skeletal muscle is likely to be the cause of susceptibility to malignant hyperthermia.

Until the exact genetic defect that causes susceptibility to malignant hyperthermia is identified direct screening of the general population for the mutation(s) that causes susceptibility will not be possible. However, as the gene has been mapped to chromosome 19 diagnosis by means of linked DNA markers can be undertaken in large known families with malignant hyperthermia which show linkage between the susceptibility trait and markers from the q12-q13.2 region of chromosome 19 . Because of the possibility of heterogeneity it is essential that at least one marker used in such a diagnosis shows linkage to the susceptibility gene in a given pedigree with a minimum lod score of $3 \cdot 0$.

We have now extended our linkage analysis of susceptibility to malignant hyperthermia to a large Irish malignant hyperthermia pedigree.

\section{Subjects and methods}

All subjects in the study are Irish by descent and $\Omega$ were referred to the testing centre for malignant $\bar{O}$ hyperthermia at University College, Cork. They were investigated with the in vitro muscle contracture test according to the European Malignant Hyperpyrexia Group protocol. ${ }^{8}$ Malignant hyperthermia susceptible (a sustained increase of $0.2 \mathrm{~g}$ in muscle tension recorded at a caffeine concentration of $\leqslant 2.0 \mathrm{mmol} / \mathrm{l}$ and at a halothane concentration of $\leqslant 2 \% \mathrm{vol} / \mathrm{vol}$ ) or normal 
Lod score for malignant hyperthermia susceptibility versus markers D19S9, CYP2A, D19S16, and $A P O C 2$ for combined sexes (equal male and female recombination rates; frequency of mutant allele at 0.001 , with penetrance of 0.99 and $1 \%$ false positive rate, allowing for potential inaccuracies in diagnosis with muscle contracture test)

Recombination frequency $(\theta)$

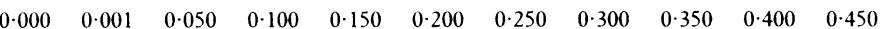

\begin{tabular}{llllllllllll}
\hline D19S9 $v$ MHS & 2.879 & 2.912 & 3.262 & 3.118 & 2.853 & 2.522 & 2.143 & 1.724 & 1.268 & 0.781 & 0.285
\end{tabular}

$\begin{array}{llllllllllll}\text { CYP2A } v \text { MHS } & 1.067 & 1.065 & 0.944 & 0.818 & 0.689 & 0.559 & 0.429 & 0.303 & 0.187 & 0.090 & 0.024\end{array}$

$\begin{array}{llllllllllll}\text { D19S16 v MHS } & 1.947 & 1.981 & 2.407 & 2.347 & 2.171 & 1.934 & 1.653 & 1.334 & 0.980 & 0.595 & 0.208\end{array}$

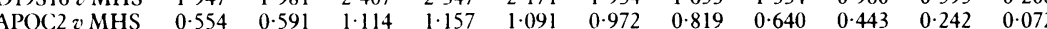

II

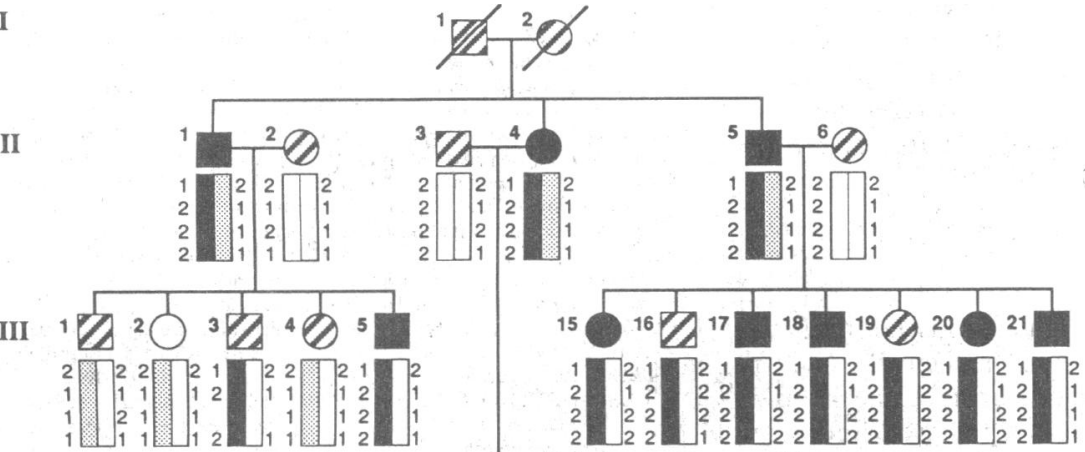

III

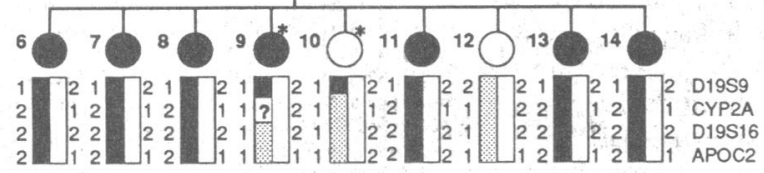

\section{Malignant hyperthermia susceptible \\ $\square \bigcirc$ Malignant hyperthermia normal \\ 12 Not tested \\ * Recombinant individuals}

FIG 3-Analysis of segregation of alleles of markers D19S9, $C Y P 2 A, D 19 S 16$, and APOC2 in large Irish malignan hyperthermia pedigree, with predicted chromosome haplotypes shown under each subject. Larger allele of restriction fragment length polymorphisms for each indicated marker is for each indicated marker allele 1. DNA denoted as allele 1 . DNA
markers are aligned according $t$ genetic and physical mapping data. ${ }^{21-2}$ Copies of chromosome 19 bearing malignant hyperthermia susceptibility gene and normal gene in the affected parent are represented by solid and spotted rectangles respectively. CYP2A haplotype for recombinant subject III-9 could not be determined phenotype (less than $0 \cdot 2 \mathrm{~g}$ in muscle tension at caffeine concentrations up to $2 \mathrm{mmol}$ or halothane concentrations up to $2 \% \mathrm{vol} / \mathrm{vol}$ ) was diagnosed; the equivocal phenotype was not diagnosed in any subjects in the pedigree. Subject III-14 was the proband who had a clinical episode of malignant hyperthermia during anaesthesia and recovered.

Samples of DNA for typing with polymorphic DNA markers were isolated from peripheral blood lymphocytes according to standard methods. ${ }^{28}$ Digestion with restriction enzymes, Southern blotting to nylon filters, and hybridisations were carried out as previously described. ${ }^{28}$ Plasmid inserts to be used as DNA probes were isolated in agarose with a low melting temperature and labelled to a specific activity of more than $1 \times 10^{9} \mathrm{cpm} / \mu \mathrm{g}$ using the random primer method..$^{29}$ Hybridisation and washing under high stringency conditions were performed as previously described. ${ }^{28}$ Data on restriction fragment length polymorphisms were analysed in conjunction with the clinical data on the family to determine which alleles of the polymorphic markers D19S9, CYP2A, D19S16, and APOC2 cosegregated with the malignant hyperthermia susceptible phenotype. The DNA probes for these markers detect polymorphisms with the restriction enzymes EcoRI (D19S9), SstI (CYP2A), TaqI (D19S16) and NcoI (APOC2). ${ }^{30-33}$

Lod scores were calculated with the LINKAGE programme ${ }^{3+}$ and assumed equal recombination rates in males and females. The population frequency of the mutant allele was kept at 0.001 and calculations were carried out assuming a penetrance of 0.99 for susceptibility and a $1 \%$ rate of false positive results, which allows for potential inaccuracies in diagnosis with the muscle contracture test.

Calculations of risk-The probability that the untested subjects carry the gene for susceptibility or the normal gene was calculated with the risk calculation option of the MLINK programme from the LINKAGE package $^{34}$ and with information on segregation from the markers D19S9, CYP2A, D19S16, and APOC2. A range of three positions for the malignant hyperthermia locus was assumed: midway between D19S9 and CYP2A, at CYP2A, and midway between CYP2A and D19S16. A dominant model was used, with assumptions of equal penetrance and equal recombination fractions in males and females. Recombination estimates between markers were derived from estimates previously published using the Centre d'Etude du Polymorphisme Humain (CEPH) panel of families or myotonic dystrophy families, or both, and are as follows: D19S9-0.05M-CYP2A-0.04M-D19S16$0.06 \mathrm{M}-\mathrm{APOC} 2 . .^{12-25}$ (A genetic distance of $0.01 \mathrm{M}$ (morgan) between markers means that the observed frequency of recombination between the markers is $1 \%$.)

\section{Results}

Twenty three members of the large Irish malignant hyperthermia pedigree were investigated for restriction fragment length polymorphisms with the polymorphic DNA markers D19S9, CYP2A, D19S16, and APOC2. The D19S9 marker was informative in the three families of the pedigree whereas CYP2A, D19S16, and APOC2 were partially informative. These markers were typed in the pedigree and two point lod scores were calculated. The maximum two point lod score generated was 3.26 at a recombination fraction of $\theta=$ 0.05 in favour of linkage of the marker D19S9 to the gene for malignant hyperthermia susceptibility (table). When the order and distance between a set of markers linked to a disease gene are known it is possible to perform a multipoint linkage analysis which allows the likelihood of the most probable location of the disease gene relative to the markers to be calculated. Multipoint linkage analysis performed in this pedigree, incorporating the markers D19S9, CYP2A, D19S16, and APOC2, resulted in a lod score of 4.73 maximising at CYP2A (fig 2). This indicates that the gene for susceptibility lies close to the CYP2A marker between D19S9 and D19S16. Investigation of the segregation pattern of alleles of the markers used in this work with the malignant hyperthermia susceptibility trait allowed us to determine the allele of each marker associated with the susceptibility trait (known as the haplotype). Inspection of the haplotypes in the malignant hyperthermia pedigree show that allele 1 of the D19S9 marker and allele 2 of the markers CYP2A, D19S16, and APOC2 cosegregate with the susceptible phenotype (fig 3). In this pedigree there were two subjects in whom recombination had occurred between closely linked markers and the susceptibility locus. In subject III-9 the alleles of the markers D19S16 and APOC2 which usually cosegregate with the normal phenotype segregated with the susceptible phenotype, indicating that recombination had occurred between D19S9 and D19S16 in this subject and that the gene for susceptibility lies proximal to D19S16. By contrast, the allele of D19S9 that usually segregates with the susceptible phenotype segregated with the normal phenotype in subject III-10, indicating that the gene for susceptibility lies distal to D19S9. Taken together, these two recombination events in conjunction with the multipoint analysis confirm the mapping of the gene for susceptibility into the interval between D19S9 and D19S16 in this malignant hyperthermia pedigree. A the marker CYP2A was only partially informative in the pedigree it was not possible to determine the allele of CYP2A which segregates with the susceptible phenotype in subject III-9.

With information on segregation of the markers 
linked to the malignant hyperthermia trait we could accurately predict the susceptible or normal phenotype in five untested subjects in the large Irish pedigree (fig 3). Investigation of the haplotypes in the untested subjects III-1 and III-4 showed that the alleles of the markers D19S9, CYP2A, D19S16, and APOC2 that usually segregated with the normal phenotype in subjects in this pedigree also segregated in these untested subjects. By contrast, the alleles of these markers that usually segregated with the susceptible phenotype in this pedigree also segregate in the untested subjects III-3, III-16, and III-19 (fig 3). The probability that the untested subjects carry the susceptibility gene or the normal gene was calculated using the MLINK programme, ${ }^{34}$ and it predicted the normal gene in subjects III-1 and III-4 and the susceptibility gene in subjects III-3, III-16, and III-19 with an accuracy of greater than $99 \cdot 7 \%$.

\section{Discussion}

This study shows that the gene for susceptibility to malignant hyperthermia maps between the DNA markers D19S9 and D19S16 on chromosome 19 in a large Irish malignant hyperthermia pedigree. Since the ryanodine receptor gene is also known to be flanked by the markers D19S9 and D19S16, ${ }^{27}$ the linkage studies presented here support the hypothesis that a defect in the ryanodine receptor gene is responsible for susceptibility. The hormone sensitive lipase (known as LIPE) gene has also been proposed as a candidate for this disorder. ${ }^{35} 36$ Since the lipase gene may also map into the interval flanked by the markers D19S9 and D19S16, ${ }^{36}$ it too remains a plausible candidate for malignant hyperthermia susceptibility.

To date about 14 families with malignant hyperthermia have been investigated by linkage analysis, ${ }^{10-12} 36$ 13 of whom show linkage between susceptibility and markers in the q12-13.2 region of chromosome 19 , whereas in one family heterogeneity was reported, indicating that some forms of the disorder may be due to a defect in a gene that is not localised to chromosome $19 q 12-13 \cdot 2$. Further extension of the linkage analysis is now necessary to establish the level of genetic heterogeneity in malignant hyperthermia susceptibility and to investigate the candidacy of the ryanodine receptor and hormone sensitive lipase genes.

In this work we diagnosed malignant hyperthermia susceptible and normal phenotypes in five untested subjects in a large Irish pedigree using linked markers. Because of the possibility of heterogeneity it was essential that at least one marker used in this diagnosis showed linkage to the gene for susceptibility in the pedigree with a minimum lod score of $3 \cdot 0$. The marker D19S9 satisfied this requirement in this pedigree, showing a lod score of 3.26 in favour of linkage to malignant hyperthermia susceptibility. With information on segregation of the markers D19S9, CYP2A, D19S16, and APOC2 the susceptible or normal phenotype could be diagnosed in five untested subjects in the pedigree, with an accuracy of greater than $99.7 \%$. The accuracy of diagnosis by this method is comparable to that of the in vitro contracture test. However, direct screening in the general population for the mutation(s) that causes susceptibility to this syndrome will not be possible until the exact genetic defect that causes susceptibility is identified.

Currently, more than 20 informative markers are available that map close to the gene for susceptibility to malignant hyperthermia on chromosome 19. The availability of such markers means that diagnosis of susceptible and normal phenotypes with linked DNA markers in place of the invasive contracture test is now possible in large malignant hyperthermia pedigrees in which an appreciable number of subjects have pre- viously been tested for susceptibility by the in vitro contracture test.

We thank the Irish Health Research Board for funding this work.

1 Gronert GA. Malignant hyperthermia. In: Engel AG, Banker BQ, eds. Myology. Vol 2. New York: McGraw-Hill, 1986:1763-84.

2 Britt BA. Dantrolene - an update. In: Britt BA, ed. Malignant hyperthermia. Boston and Amsterdam: Martinus-Nijhoff, 1987:325-67.

3 Engel AG, Banker BQ, eds. Myology. Vol 2. New York: McGraw-Hill, 1986:iv.

4 Heffron JJA. Malignant hyperthermia: biochemical aspects of the acute episode. Br $\mathcal{F}$ Anaesth 1988;60:274-8

5 Ellis FR, Heffron JJA. Clinical and biochemical aspects of malignant hyperthermia. In: Atkinson RS, Adams AP, eds. Recent advances in

6 Britt BA, Locher WG, Kalow W. Hereditary aspects of malignant hyperthermia. Canadian Anaesthetists Society fournal 1969;16:89-98.

Britt BA, Kalow W. Malignant hyperthermia: a statistical review. Canadian Anaesthetists Society foumal 1970;17:293-315.

8 European Malignant Hyperpyrexia Group. A protocol for investigation of malignant hyperpyrexia susceptibility. Br $\mathcal{A}$ Anaesth 1984;56:1267-71.

9 Ording $\mathrm{H}$. The European $\mathrm{MH}$ group: protocol for in vitro diagnosis of susceptibility to $\mathrm{MH}$ and preliminary results. In: Britt BA, ed. Maligna hyperthermia. Boston and Amsterdam: Martinus-Nijhoff, 1987:267-77.

10 McCarthy TV, Healy SJM, Lehane M, Heffron JJA. Recent developments in the molecular genetics of malignant hyperthermia: implications for future diagnosis at the DNA level. Acta Anaesthesiol Belg 1990;41:107-12.

11 McCarthy TV, Healy SJM, Heffron JJA, Lehane M, Deufel T, LehmannHorn F, et al. Localisation of the malignant hyperthermia susceptibility locus to human chromosome 19q12-13-2. Nature 1990;343:562-4.

12 MacLennan DH, Duff C, Zorzato F, Fujii J, Phillips M, Korneluk RG, et al. The ryanodine receptor gene: a candidate gene for the predisposition to malignant hyperthermia. Nature 1990;343:559-61.

13 Kalow W. Inheritance of malignant hyperthermia-a review of published data. In: Britt BA, ed. Malignant hyperthermia. Boston and Amsterdam: Martinus-Nijhoff, 1987:155-79.

14 Lopez J, Alamo LA, Caputo C, Wikinski J, Ledezma D. Intracellular ionized calcium concentration in muscle from humans with malignant hyperthermia. Muscle Nerve 1985;8:355-8.

15 laizzo PA, Klein W, Lehmann-Horn F. Fura-2 detected myoplasmic calcium and its correlation with contracture force in skeletal muscle from normal and malignant hyperthermia susceptible pigs. Pflugers Arch 1988;411:648-53.

16 Nelson TE. Abnormality in calcium release from skeletal sarcoplasmic reticulum of pigs susceptible to malignant hyperthermia. $\mathcal{f}$ Clin Invest 1983;72:862-70.

17 Ohnishi ST, Taylor SR, Gronert GA. Calcium-induced $\mathrm{Ca}^{* *}$ release from sarcoplasmic reticulum of pigs susceptible to malignant hyperthermia. FEBS Lett 1983;161:103-7

18 Mickelson JR, Gallant EM, Litterer LA, Johnson KM, Rempel WE, Louis $\mathrm{CF}$. Abnormal sarcoplasmic reticulum ryanodine receptor in malignant hyperthermia. I Biol Chem 1988;263:9310-5.

19 Ott J. Analysis of human genetic linkage. Baltimore: Johns Hopkins University Press, 1985.

20 Davies KE, Read AP. Molecular basis of inherited disease in focus. Oxford: IRL Press, 1988.

21 Harley HG, Brook JD, Rundle SA, Walsh KV, Sarfarazi M, Johnson K, et al. A map of the long arm of chromosome 19: an order for twelve polymorphic markers and the myotonic dystrophy gene. Cytogenet Cell Genet 1989;51 markers and the myotonic dystrophy gene. Cyto
$(1-4): 1011$. (Human gene mapping 10 abstract.)

22 Nakamura Y, Lathrop M, O'connell P, Leppert M, Lalouel JM, White R. A primary map of ten DNA markers and two serological protein markers for human chromosome 19. Genomics 1988;3:67-81.

23 Brunner HG, Smeets H, Lambermon HMM, Coerwinkel-Driessen M, van Oost BA, Wieringa B, et al. A multipoint linkage map around the locus for myotonic dystrophy on chromosome 19. Genomics 1989;5:589-95.

24 Schonk D, Coerwinkel-Driessen M, van Dalen I, Oerlemans F, Smeets B, Schepens $\mathrm{J}$, et al. Definition of subchromosomal intervals around the myotonic dystrophy gene region at 19q. Genomics 1989;4:384-96.

25 Ropers HH, Pericak-Vance A. Report of the committee on the constitution of chromosome 19. Cytogenet Cell Genet 1990;55(1-4):218-29. (Human Gene Mapping 10.5.

26 Schonk D, van Dijk PE, Riegman P, Trapman J, Holm C, Craig IW, et al. Subregional assignment of six genes on chromosome 19Q. Human Cytogenet Cell Genet 1990;55(1-4):1075. (Human Gene Mapping 10.5.)

27 MacKenzie AE, Korneluk RG, Zorzato F, Fujii J, Phillips M, lles D, et al. The human ryanodine receptor gene: its mapping to $19 \mathrm{q} 13.1$, placement in a chromosome 19 linkage group, and exclusion as the gene causing myotonic dystrophy. Am f Hum Genet 1990;46:1082-9.

28 Sambrook J, Fritsh EF, Maniatis T. Molecular cloning. A laboratory manual. 2nd ed. New York: Cold Spring Harbor Laboratory, 1989.

29 Feinberg AP, Vogelstein B. A technique for radiolabeling DNA restriction endonuclease fragments to high specific activity. Anal Biochem 1983;132: 6-13.

30 Brook JD, Shaw DJ, Meredith AL, Bruns GAP, Harper PS. Localisation of genetic markers and orientation of the linkage group on chromosome 19. Hum Genet 1984;68:282-5.

31 Wainwright BJ, Watson EK, Shephard EA, Phillips IR. RFLP for a human cytochrome P-450 gene at 19q13.1-qter. Nucleic Acids Res 1985;13:4610.

32 Schepens J, Smeets $\mathrm{H}$, Hulsebos T, Brunner H, Wieringa B. Isolation of a polymorphic DNA sequence pJSB1I (D19S16) from the human chromosome 19cen-q13.2 region linked to the myotonic dystrophy (DM) gene. Nucleic Acids Res 1987;15:3192.

33 Humphries SE, Jowett NI, William L, Rees A, Vella M, Kessling A, et al. A DNA polymorphism adjacent to the human apolipoprotein CII gene. Mol Biol Med 1983;1:463-71.

34 Lathrop GM, Lalouel JM, Jullier C, Ott J. Strategies for multilocus linkage analysis in humans. Proc Natl Acad Sci USA 1984;81:3443-6.

35 Levitt RC, McKusick VA, Fletcher JE, Rosenberg H. Gene candidate. Nature 1990;345:297-8.

36 Levitt RC, McKusick VA, Fletcher JE, Rosenberg H. Malignant hyperthermia susceptibility (MHS): hormone sensitive lipase (LIPE) suggested as a candidate gene. $\mathcal{F}$ Neurol Sci (suppl) 1990:513-4.

(Accepted 6 August 1991) 